\title{
Influence of enhanced recovery after surgery (ERAS) on patients receiving lung resection: a retrospective study of 1749 cases
}

Chunmei Wang ${ }^{1 \dagger}$, Yutian Lai ${ }^{3 \dagger}$, Pengfei Li ${ }^{1}$, Jianhuan Su² and Guowei Che ${ }^{1^{*}}$

\begin{abstract}
Background: The study aimed to evaluate the outcomes following the implementation of enhanced recovery after surgery (ERAS) for patients undergoing lung cancer surgery.

Method: A retrospective cohort study involving 1749 patients with lung cancer undergoing pulmonary resection was conducted. The patients were divided into two time period groups for analysis (routine pathway and ERAS pathway). Logistic regression analysis was performed to assess the risks of developing postoperative pulmonary complications.

Results: Among the 1749 patients, 691 were stratified into the ERAS group, and 1058 in to the routine group. The ERAS group presented with shorter postoperative in-hospital length of stay (LOS) (4.0 vs 6.0, $P<0.001)$, total LOS (10.0 vs. 13.0 days, $P<0.001)$, and lower total in-hospital costs $(P<0.001)$, including material $(P<0.001)$ and drug expenses $(P<0.001)$. Furthermore, the ERAS group also presented with a lower occurrence of postoperative pulmonary complications (PPCs) than the routine group (15.2\% vs. 19.5\%, $P=0.022)$. Likewise, a significantly lower occurrence of pneumonia ( $8.4 \%$ vs. $14.2 \%, \mathrm{P}<0.001)$ and atelectasis $(5.9 \%$ vs. $9.8 \%, \mathrm{P}=0.004)$ was found in the ERAS group. Regarding the binary logistic regression, the ERAS intervention was the sole independent factor for the occurrence of PPCs (OR: 0.601, 95\% Cl 0.434-0.824, $\mathrm{P}=0.002$ ). In addition, age (OR: 1.032, 95\% Cl 1.018-1.046), COPD (OR: 1.792, 95\% Cl 1.196-2.686), and FEV1 (OR: 0.205, 95\% Cl 0.125-0.339) were also independent predictors of PPCs.

Conclusion: Implementation of an ERAS pathway shows improved postoperative outcomes, including shortened LOS, lower in-hospital costs, and reduced occurrence of PPCs, providing benefits to the postoperative recovery of patients with lung cancer undergoing surgical treatment.
\end{abstract}

Keywords: Enhanced recovery after surgery, Lung cancer, Postoperative pulmonary complications, Thoracic surgery

\section{Background}

Thoracic surgery is the optimal therapy for early or resectable lung cancer $[1,2]$; however, it remains an invasive and traumatic procedure for the patients, particularly for those with lung dysfunction or a poor health

*Correspondence: hx_guowei_che@foxmail.com

${ }^{\dagger}$ Chunmei Wang and Yutian Lai should be considered as co-first authors

${ }^{1}$ Department of Thoracic Surgery, West China Hospital, Sichuan

University, Chengdu 610041, People's Republic of China

Full list of author information is available at the end of the article status [3]. Minimally invasive surgeries, including videoassisted thoracoscopic surgery (VATS), are preferred for early stage lung cancer but remain limited by side effects and surgical stress, with a morbidity of $20.8-34.1 \%$ after lung cancer surgery $[4,5]$. The search for better recovery from surgical injury is an urgent issue for lung cancer therapy.

Recently, researchers have begun to pay increasing attention to patient recovery after surgery [6, 7]. Enhanced recovery after surgery (ERAS), an evidencebased multimodal protocol for perioperative care 
proposed in colorectal surgery in the late 1990s, combines various synergistic elements throughout the hospital stay, from the first consultation to discharge. ERAS strategies have been considerably developed and enrolled a growing number of elements in all aspects of perioperative care, aiming to largely reduce the stress response to surgery, complications, and the in-hospital length of stay (LOS) after surgery. Great effort has been made to improve or optimize perioperative management.

A series of studies have focused on ERAS strategies for thoracic surgery in the past few years, indicating that ERAS can efficiently minimize the surgical trauma, reduce postoperative complications, improve quality of life before and after surgery, shorten hospital stay and finally decrease the financial burden of patient [811]. The research of ERAS still needs to be studied and refined [12-16]. A larger sample size and more diverse regions of study are needed to determine the effectiveness of ERAS strategies.

For this reason, we conducted this study to evaluate the clinical outcomes of an ERAS program among patients with cancer after anatomical lung resection.

\section{Method}

The ERAS protocol was developed and implemented in the thoracic department of our hospital following approval from the China International Exchange and Promotion Association for Medical and Healthcare (CMAP) as the training center for ERAS teaching and practices. The ERAS team, consisting of surgeons, physical therapists, nutritionists, specialized nurses and anesthesiologists, was created in 2015.

\section{Patients}

The patients were divided into two time period groups for analysis (routine pathway: 2012.01.01-2014.12.31 and ERAS pathway: 2016.01.01-2017.12.31). A washout period of 1 year was set to diminish the impact of carryover effects. The clinical outcomes between the two groups were comparatively analyzed. The inclusion criteria were as follows: (1) diagnosis with primary non-small-cell lung cancer (NSCLC); (2) anatomical lung resection, including lobectomy and segmentectomy; and (3) age $\geq 18$ years old. Exclusive criteria included (1) benign lesions or other pathological types except NSCLC; (2) other surgical approaches except anatomical lung resection; and (3) age $<18$ years old. A total of 1058 patients who underwent anatomical lung resection in our department between 2012.01.01 and 2014.12.31 were selected. During this period, patients underwent the routine pathway and were enrolled into the pre-ERAS group; 691 subjects included between 2016.01.01 and 2017.12.31 and who underwent the standard ERAS pathway were classified into the ERAS group.

\section{Comparison of the ERAS program and the routine pathway} The ERAS program standardizes various the elements throughout hospitalization. The whole ERAS program implemented in this study included ERAS education and consultation, venous thromboembolisms (VTEs) prophylaxis, chest tubes, urinary catheters, postoperative pain and nutrition management, anesthesia, perioperative respiratory training, and mobilization. During respiratory training and mobilization, patients were encouraged to finish 20 breaths/session for 3 sessions/day via a volumetric incentive spirometer (HUDSON RCI 2500, TeleflexInc, USA) perioperatively, under the guidance and supervision of physical therapists. Moreover, a specialist nurse recorded the patient performance. The nurse of the VTE management group evaluated the VTE risk via the Caprini Assessment Scale [17, 18] and used low-molecular-weight heparin (LMWH) perioperatively for VTE prophylaxis [19]. According to the Caprini score, patients were divided into low-, moderate- and high-risk groups. The low- and moderate-risk groups received enoxaparin (4000 Axa IU, q.d) from referral to discharge, while the high-risk group received enoxaparin (4000 AxaIU, q.d) from referral to 2-4 weeks after discharge. Coagulation function was monitored. For the pre-ERAS group, patients did not receive a Caprini score or standardized VTE prophylaxis. The specialist nurse supervised and assessed the postoperative pain intensity (NRS score* 6 , $12,18,24,36,48 \mathrm{~h}$ after surgery) and thereby adjusted the analgesics if necessary. Postoperative analgesia was assessed by a standard protocol-based multimodal approach: acetaminophen $1000 \mathrm{mg}$ i.v. $\times 48 \mathrm{~h}$, then p.o., ketorolac $15 \mathrm{mg}$ i.v. $\times 48 \mathrm{~h}$, then NSAIDS p.o., and gabapentin $300 \mathrm{mg}$ p.o. Breakthrough pain was treated as follows: tramadol $50 \mathrm{mg}$ p.o., then oral or i.v. opioids if necessary (sustained pain score 4/10). Other elements of the ERAS program are listed in Table 1.

\section{Data collection and statistical analysis}

Patient demographics, comorbidities, and clinical outcomes during hospitalization, including length of stay, readmissions, reoperations, and postoperative pulmonary complications (PPCs), were retrospectively recorded in both the ERAS and pre-ERAS groups. Ten types of criteria for PPCs were investigated on the basis of the STS/ESTS definitions [20]: (1) pneumonia; (2) atelectasis documented clinically or radiographically; (3) respiratory/heart failure or adult breathing distress syndrome (ADRS); (4) mechanical ventilation $>48 \mathrm{~h}$; (5) $>7$ days air leak; (6) pulmonary embolism; (7) empyema; (8) chyle 
Table 1 Comparison of Pre-ERAS (routine) pathway and ERAS pathway

\begin{tabular}{|c|c|}
\hline Pre-ERAS (routine) pathway & ERAS pathway \\
\hline General patient admission education introduced by video & $\begin{array}{l}\text { The content included general patient admission education, instruction about ERAS } \\
\text { principles and ERAS member responses to the patients. The specialized nurse was mainly } \\
\text { responsible for the session. Smoking and alcohol cessation for } 2 \text { weeks and } 4 \text { weeks } \\
\text { respectively }\end{array}$ \\
\hline \multicolumn{2}{|l|}{ Perioperative respiratory training and mobilization } \\
\hline No & $\begin{array}{l}\text { A volumetric Incentive spirometer (HUDSON RCI } 2500 \text {, TeleflexInc, USA) was provided after } \\
\text { the agreement of the patients. The physical therapists would teach the patients and } \\
\text { supervised the patients' respiratory training during the in-hospital period } \\
\text { On the first day after the operation, the electrocardiograph monitoring will be withdrawn } \\
\text { and the patient will get out of bed for activities under professional escort. If the patient } \\
\text { cannot get out of bed due to pain or anesthesia, the patient will also be encouraged to } \\
\text { sit up or stand up beside the bed }\end{array}$ \\
\hline \multicolumn{2}{|l|}{ VTE management } \\
\hline No standardized management & $\begin{array}{l}\text { 1. VTE prophylaxis education preoperative VTE assessment risk rating } \\
\text { 2. LMWH use for VTE prophylaxis during perioperative period } \\
\text { 3. Early mobilization after surgery }\end{array}$ \\
\hline \multicolumn{2}{|l|}{ Chest tube management } \\
\hline $\begin{array}{l}\text { 1. Traditionally using } 228-\mathrm{F} \text { chest tube } \\
\text { 2. Chest tube removal after drainage volume }<200 \mathrm{ml}\end{array}$ & $\begin{array}{l}\text { 1. Small-bore chest tube ( } 18 \text {-Floyle) } \\
\text { 2. Drain removed }<400 \mathrm{ml} / 24 \mathrm{~h} \text { and no air flow }\end{array}$ \\
\hline \multicolumn{2}{|l|}{ Urinary catheter management } \\
\hline Urinary catheter was routinely used & No urinary catheter \\
\hline \multicolumn{2}{|l|}{ Postoperative pain management } \\
\hline Non-standardized management & $\begin{array}{l}\text { 1. Specialized nurse supervised and assess the pain intensity (NRS score at } 6 \mathrm{~h}, 12 \mathrm{~h}, 18 \mathrm{~h} \text {, } \\
24 \mathrm{~h}, 36 \mathrm{~h}, 48 \mathrm{~h} \text { after the surgery), and based on it, adjustment of analgesics would be } \\
\text { performed if necessary } \\
\text { 2. Standardized protocol-based multimodal approach to post-operative analgesia } \\
\text { 3. Specialized nurses open thoracic pain clinics, aiming at follow-up of postoperative pain }\end{array}$ \\
\hline \multicolumn{2}{|l|}{ Postoperative nutrition management } \\
\hline Non-standardized management & $\begin{array}{l}\text { 1. Early Oral Intake } \\
\text { 2. Medium chain triglyceride }(\mathrm{MCT}) \text { diet supported by nutriology department }\end{array}$ \\
\hline
\end{tabular}

VTE venous thromboembolism; LMWH low-molecular-weight heparin, NRS numeric rating scales, MCT medium chain triglyceride

leak; (9) bronchopleural fistula; and (10) return to the ICU.

Continuous variables are expressed as the means and standard deviations (SDs). Data that did not follow a normal distribution are presented as the median and range, and binary variables are presented as proportions. Data were evaluated via the chi-square test, Fisher's exact test, or Student's t-test as appropriate. Statistical analyses were performed on SPSS 21.0 at the significance level of 0.05 .

\section{Results}

\section{Clinical characteristics}

The 1749 patients were divided into an ERAS group $(\mathrm{n}=691)$ and a routine group $(\mathrm{n}=1058)$. Clinical data including age, sex, comorbidities, pathologic stage and type, pulmonary function, and amount of bleeding during the operation were compared between groups (Table 2). Compared with the routine pathway group, the ERAS group was found to have a higher proportion of VATS $(74.2 \%$ vs. $65.3 \%)$, shorter postoperative in-hospital LOS $[4.0(2.0,6.0)$ vs. $6.0(4.0,9.0)]$, shorter total LOS $[10.0(7.0,13.0)$ vs. $13.0(10.0,16.0)$ days], and lower total in-hospital costs, including material and drug expenses, all with significant differences (all $\mathrm{P}<0.001$ ). Regarding to drainage, a lower drainage volume $[540.0(275.0,1170.5)$ vs. $700.0(150,1710) \mathrm{ml}]$ and a shorter duration of drainage $[3.0(2.0,5.0)$ vs. $5.0(4.0,7.0)$ days] were observed in the ERAS group (both $\mathrm{P}<0.001$ ).

\section{Occurrence of PPCs}

Compared with the routine pathway group, the ERAS group presented with a lower occurrence of PPCs $(15.2 \%$, $105 / 691$ vs. $19.5 \%, 206 / 1058, P=0.022)$ and a significantly lower occurrence of pneumonia $(8.4 \%, 58 / 691$ vs. $14.2 \%, 150 / 1058, \mathrm{P}<0.001)$ or atelectasis $(5.9 \%, 41 / 691$ vs. $9.8 \%, 104 / 1058, \mathrm{P}=0.004$ ) (Table 3 ).

We also compared clinical characteristics between patients with $(n=311)$ and without PPCs $(n=1438)$. Significant differences between groups were found in age, FEV1, amount of bleeding during the operation, COPD, total or postoperative LOS, total in-hospital costs, drug costs, duration of drainage (all $\mathrm{P}<0.001)$, FVC $(\mathrm{P}=0.043)$, and surgery time $(\mathrm{P}=0.021)($ Table 4$)$. 
Table 2 Clinical characteristic between two groups

\begin{tabular}{|c|c|c|c|}
\hline & $\begin{array}{l}\text { ERAS group } \\
n=691\end{array}$ & $\begin{array}{l}\text { Routine group } \\
n=1058\end{array}$ & $P$ \\
\hline \multicolumn{4}{|l|}{ Basic clinical characteristics } \\
\hline Age $(\text { year })^{a}$ & $61.0(56.0,67.0)$ & $61.0(53.0,68.0)$ & 0.688 \\
\hline $\operatorname{Sex}(M / F)$ & $351 / 340$ & $527 / 531$ & 0.687 \\
\hline \multicolumn{4}{|l|}{ Comorbidities } \\
\hline Hypertension (Y/N) & $111 / 580$ & 151/907 & 0.305 \\
\hline $\operatorname{COPD}(\mathrm{Y} / \mathrm{N})$ & $71 / 620$ & $97 / 961$ & 0.443 \\
\hline Diabetes mellitus (Y/N) & $62 / 629$ & $88 / 970$ & 0.633 \\
\hline Smoking status (Y/N) & $182 / 509$ & 249/809 & 0.595 \\
\hline \multicolumn{4}{|l|}{ Pulmonary function } \\
\hline FEV1 $(L)^{a}$ & $2.29(1.71,2.73)$ & $2.28(2.12,2.44)$ & 0.807 \\
\hline $\mathrm{FVC}(\mathrm{L})^{\mathrm{a}}$ & $3.26(2.72,3.71)$ & $3.20(2.94,3.48)$ & 0.169 \\
\hline \multicolumn{4}{|l|}{ Surgical approach (n \%) } \\
\hline VATS & $513(74.2)$ & $691(65.3)$ & $<0.001$ \\
\hline Open & $178(25.8)$ & $367(34.7)$ & \\
\hline Amount of bleeding in operation ${ }^{a}$ & $50.0(20.0,70.0)$ & $180.0(140.0,220.0)$ & 0.628 \\
\hline Surgery time ${ }^{a}$ & $90.0(70.0,120.0)$ & $120.0(90.0,150.0)$ & $<0.001$ \\
\hline Postoperative LOSa & $4.0(2.0,6.0)$ & $6.0(4.0,9.0)$ & $<0.001$ \\
\hline Total LOS & $10.0(7.0,13.0)$ & $13.0(10.0,16.0)$ & $<0.001$ \\
\hline \multicolumn{4}{|l|}{ Pathological stage, (n \%) } \\
\hline Stage I & $313(45.3)$ & $506(47.8)$ & 0.589 \\
\hline Stage II & $292(42.3)$ & $421(39.8)$ & \\
\hline Stage III & 75 (10.9) & $119(11.2)$ & \\
\hline Stage IV & $11(1.6)$ & $12(1.1)$ & \\
\hline \multicolumn{4}{|l|}{ Pathological type (n \%) } \\
\hline Adenocarcinoma & $473(68.5)$ & $740(69.9)$ & 0.799 \\
\hline Squamous cell carcinoma & $192(27.8)$ & $281(26.6)$ & \\
\hline Other & $26(3.8)$ & $37(3.5)$ & \\
\hline \multicolumn{4}{|l|}{ In-hospital expense, $¥$} \\
\hline Total $^{\mathrm{a}}$ & $46,047.7(39,068.7,52,733.8)$ & $47,583.0(43,761.6,51,839.6)$ & $<0.001$ \\
\hline Material cost ${ }^{a}$ & $23,742.6(19,588.2,27,844.8)$ & $25,040.4(21,439.5,29,871.5)$ & $<0.001$ \\
\hline Drug $\cos ^{\mathrm{a}}$ & $7633.5(5537.0,10,100.3)$ & $8157.6(6453.2,11,665.5)$ & $<0.001$ \\
\hline Drainage volume $^{a}$ & $540.0(275.0,1170.5)$ & $700.0(150,1710)$ & $<0.001$ \\
\hline Duration of drainage $\mathrm{e}^{\mathrm{a}}$ & $3.0(2.0,5.0)$ & $5.0(4.0,7.0)$ & $<0.001$ \\
\hline
\end{tabular}

ERAS enhanced recovery after surgery, COPD chronic obstructive pulmonary disease defined as FEV1/FVC $<70 \%$ and FEV1 $<80 \%$ of predicted, FEV 1 forced expiratory volume in $1 \mathrm{~s}$, FVC forced vital capacity, VATS video assisted thoracic surgery, LOS length of stay

a Non-normal distribution variables described as median (interquartile)

$¥$ China Yuan

The relevant independent factors for PPCs, pneumonia or atelectasis were investigated via binary logistic regression. The variables analyzed included sex, age, smoking status, comorbidities, FEV1, FVC, surgical approach, amount of bleeding during the operation, surgery time, and the presence of early stage (stage I) cancer. The ERAS intervention was found to be an independent factor for the occurrence of PPCs (OR: 0.601, 95\% CI 0.434-0.824, $\mathrm{P}=0.002$ ), pneumonia (OR: $0.371,95 \% \mathrm{CI}$ 0.243-0.566, $\mathrm{P}<0.001)$, and atelectasis (OR: $0.431,95 \%$
CI 0.271-0.687, $\mathrm{P}<0.001$ ) (Table 5). As listed in Table 5, ERAS intervention, age, COPD, and FEV1 were independent predictors for PPCs.

\section{Discussion}

Lung cancer continues to ranks first among all cancers in terms of incidence and death rates worldwide, including in China. Surgery is deemed the optimal strategy or option for patients with early or resectable tumors. Due to poor lung function and sequential PPCs, patients with 
Table 3 Postoperative between the two groups

\begin{tabular}{lccr}
\hline & $\begin{array}{c}\text { ERAS group } \\
n=691\end{array}$ & $\begin{array}{l}\text { Routine group } \\
n=1058\end{array}$ & P value \\
\hline PPCs rate, (n \%) & $105(15.2)$ & $206(19.5)$ & 0.022 \\
Pneumonia & $58(8.4)$ & $150(14.2)$ & $<0.001$ \\
Atelectasis & $41(5.9)$ & $104(9.8)$ & 0.004 \\
Pulmonary embolism & $2(0.3)$ & $4(0.4)$ & 1.000 \\
Respiratory/heart failure or & $11(1.6)$ & $12(1.1)$ & 0.411 \\
$\quad$ ADRS & $6(0.9)$ & $10(0.9)$ & 0.869 \\
Bronchopleural fistula & $18(2.6)$ & $35(3.3)$ & 0.239 \\
Mechanical ventilation $>48 \mathrm{~h}$ & $11(1.0)$ & 0.307 \\
Empyema & $45(5.6)$ & $78(7.4)$ & 0.055 \\
Air leak & $7(1.0)$ & $11(1.0)$ & 0.957 \\
Back to ICU & $4(0.6)$ & $6(0.6)$ & 1.000 \\
Death &
\end{tabular}

PPCS postoperative pulmonary complications, ERAS enhanced recovery after surgery pulmonary complications

0.022

0.001

000

411

0.869

0.239

0.307

0.055

0.957

(1)

(ans

woun mainstream approach for lung cancer surgery, espe-
cially at early-stages [28-30]. (3) The components of ERAS programs vary among different institutions, and

Table 4 Comparison between PPCs group and non-PPCs group

\begin{tabular}{|c|c|c|c|}
\hline & $\begin{array}{l}\text { PPCs group } \\
n=311\end{array}$ & $\begin{array}{l}\text { Non-PPCs group } \\
n=1438\end{array}$ & $P$ \\
\hline \multicolumn{4}{|l|}{ Basic clinical characteristics } \\
\hline Age $(\text { year })^{\mathrm{a}}$ & $62.0(56.0,73.0)$ & $60.0(54.0,66.0)$ & $<0.001$ \\
\hline $\operatorname{Sex}(M / F)$ & $148 / 163$ & 730/708 & 0.310 \\
\hline \multicolumn{4}{|l|}{ Comorbidities } \\
\hline Hypertension (Y/N) & $48 / 263$ & $214 / 1224$ & 0.805 \\
\hline $\operatorname{COPD}(\mathrm{Y} / \mathrm{N})$ & $46 / 265$ & $122 / 1316$ & 0.001 \\
\hline Diabetes mellitus (Y/N) & $27 / 284$ & $123 / 1315$ & 0.942 \\
\hline Smoking status (Y/N) & $72 / 239$ & $370 / 1068$ & 0.343 \\
\hline ERAS program (Y/N) & $105 / 206$ & $852 / 586$ & 0.022 \\
\hline Pathological stage I or $0,(\mathrm{Y} / \mathrm{N})$ & $140 / 171$ & $679 / 759$ & 0.480 \\
\hline VATS approach & 203/108 & $431 / 1001$ & 0.134 \\
\hline \multicolumn{4}{|l|}{ Pulmonary function } \\
\hline FEV1 $(L)^{\mathrm{a}}$ & $2.13(1.90,2.31)$ & $2.32(2.09,2.52)$ & $<0.001$ \\
\hline $\mathrm{FVC}(\mathrm{L})^{\mathrm{a}}$ & $3.20(2.84,3.44)$ & $3.23(2.873 .56)$ & 0.043 \\
\hline Amount of bleeding in operation ${ }^{a}$ & $150.0(100.0,200.0)$ & $50.0(150.0,200.0)$ & 0.022 \\
\hline Surgery time $\mathrm{a}^{\mathrm{a}}$ & $120.0(90.0,140.0)$ & $110.0(80.0,140.0)$ & 0.021 \\
\hline Postoperative LOSa & $9.0(6.0,12.0)$ & $4.0(3.0,7.0)$ & $<0.001$ \\
\hline Total LOSa & $16.0(12.0,19.0)$ & $8.0(11.0,14.0)$ & $<0.001$ \\
\hline \multicolumn{4}{|l|}{ In-hospital expense, $¥$} \\
\hline Total $^{a}$ & $52,649.6(46,815.1,61,097.0)$ & $46,151.2(41,919.2,50,908.2)$ & $<0.001$ \\
\hline Material cost ${ }^{\mathrm{a}}$ & $24,567.0(19,886.2,31,942.8)$ & $24,486.5(20,925.8,28,342.1)$ & 0.085 \\
\hline Drug cost ${ }^{a}$ & $14,411.3(11,127.8,16,427.8)$ & $7322.0(5980.1,9655.5)$ & $<0.001$ \\
\hline Drainage volume $\mathrm{a}^{\mathrm{a}}$ & $700(230.0,1600.0)$ & $590.0(180,1470)$ & 0.095 \\
\hline Duration of drainage $\mathrm{e}^{\mathrm{a}}$ & $5.0(3.0,8.0)$ & $4.0(3.0,6.0)$ & $<0.001$ \\
\hline
\end{tabular}

PPCS postoperative pulmonary complications, ERAS enhanced recovery after surgery, COPD chronic obstructive pulmonary disease defined as FEV1/FVC $<70 \%$ and FEV $1<80 \%$ of predicted, FEV1 forced expiratory volume in $1 \mathrm{~s}$, FVC forced vital capacity, VATS video assisted thoracic surgery, LOS length of stay

a Non-normal distribution variables described as median (interquartile)

$¥$ China Yuan 
Table 5 Multivariable analysis $(n=101)$ of risk to postoperative pulmonary complications (PPCs) ${ }^{\mathbf{a}}$, pneumonia and atelectasis

\begin{tabular}{llr}
\hline Variables & OR $(95 \% \mathrm{Cl})$ & P value \\
\hline PPCS & & \\
ERAS intervention & $0.601(0.434-0.824)$ & 0.002 \\
Age & $1.032(1.018-1.046)$ & $<0.001$ \\
COPD & $1.792(1.196-2.686)$ & 0.005 \\
FEV1 & $0.318(0.221-0.457)$ & $<0.001$ \\
Pneumonia & & \\
ERAS intervention & $0.371(0.243-0.566)$ & $<0.001$ \\
Age & $1.039(1.022-1.055)$ & $<0.001$ \\
FEV1 & $0.205(0.125-0.339)$ & $<0.001$ \\
Atelectasis & & \\
ERAS intervention & $0.431(0.271-0.687)$ & $<0.001$ \\
Early stage & $0.676(0.469-0.975)$ & 0.036 \\
FEV1 & $0.272(0.157-0.471)$ & $<0.001$ \\
\hline
\end{tabular}

$P P C s$ postoperative pulmonary complications

a The multivariable analysis was performed via binary logistic regression

the practice of ERAS elements likely relies on clinical experience. Many elements of ERAS programs have become routine and it is difficult to judge whether temporal changes in practice can improve the outcomes, rather than the use of the ERAS pathway per se.

Our ERAS multidisciplinary and collaborative team was established in 2015 to more professionally and effectively carry out the ERAS pathway. The patients are counselled and supervised by trained nurses to complete the ERAS phases. Breathing exercise and postoperative nutrition procedures are conducted by specialized physical therapists and nutritionists.

We found that the proportion of patients who underwent the ERAS pathway with early-stage (stage 0 or I) cancer were not significantly greater than those of patients who underwent the routine pathway, but the proportion of VATS among ERAS patients increased. The possible reasons were that the wide promotion of minimally invasive surgery and the commonly accepted or recognized advantaged of VATS, especially for young surgeons. From the surgeons' perspective, the implementation of minimally invasive surgery is also an important element of the ERAS protocol, as it offers patients a shorter surgical time, less intraoperative blood loss, postoperative pain and surgical trauma, and faster sequential recovery after surgery. In the guidelines for ERAS drafted by the ERAS Society and the European Society of Thoracic Surgeons (ESTS), a VATS approach for lung resection is recommended for earlystage lung cancer with a high evidence level and strong recommendation grade [26]. According to the results, lower surgery time and less blood loss were observed in the ERAS group, showing the potential benefits that this minimally invasive approach provided to the patients' postoperative recovery.

PPCs are considered important negative influences on recovery outcomes, increasing the risk of mortality. Evidence shows that ERAS regimens integrating effective perioperative courses prevent PPCs for patients with lung cancer undergoing lung resection [31]. Controversially, Brunelli et al. reported no significant difference in postoperative morbidity after the use of an ERAS program. Potential reasons include the lack of a washout period, study heterogeneity, the exact structure of the ERAS program, and the quality of implementation or patient selection [32]. What's more, their conventional care was very similar to ERAS before they introduced ERAS. We found lower occurrences of PPCs and pneumonia in the ERAS group than in the routine pathway group. Theoretically, elements including the VATS approach, pain, and VTE management may jointly improve postoperative recovery and decrease the PPC rate. Furthermore, the results of multivariable analysis revealed that the ERAS intervention was an independent factor of PPCs as well as of pneumonia and atelectasis, validating its effectiveness in improving postoperative recovery for those patients. Another essential variable was LOS. Proper pain control, chest tube removal and few complications contribute to a shorter LOS, indicating better postoperative recovery. Early mobilization is the most important predictor of reduced morbidity [11]. One recent systematic review summarized RCTs concerning ERAS and reported that four of the five RCTs indicated the mean LOS was significantly shortened by the ERAS [33]. Our study reveals shorter LOS and postoperative LOS in ERAS group, suggesting better recovery in those population. Meanwhile, lower in-hospital expenses including drug costs and a shorter duration for the indwelling chest tube were found in the ERAS group, which also provided evidence of the effectiveness of the ERAS program.

In the present study, we also explored the predictive factors for developing PPCs. In addition to the ERAS intervention, age, COPD, and FEV1 can also significantly and independently predict the risk of developing PPCs.

The study has some limitations that should not be ignored. First, all the patients were selected from a single regional center by a small group of surgeons, and propensity-matching was not analyzed in the control group. As a retrospective study, the lack of randomization limited the control of intergroup bias. We enrolled the patients over a large time span of approximately 5 years. Therefore, better outcome for the ERAS group may be the result of the bias caused by the increased experience of our team. Second, the effects of the ERAS program, the sole effects of standardization, and 
whether temporal changes in practice improved the outcomes, rather than the use of the ERAS pathway per se cannot be easily determined. Third, the selection of patients receiving anatomical resection and the exclusion of patients undergoing wedge section and pneumonectomy resulted in a relevant bias and the sequential limitation of generalization of the conclusions. Moreover, we did not detail the in-hospital costs, so we cannot fully explore the economic outcomes of the ERAS program. Finally, we did not assess the pain control and nutrition-related variables between groups, and could not directly assess the role of pain and nutrition management in the ERAS program.

\section{Conclusion}

The use of an ERAS pathway is associated with improved postoperative outcomes, including a shorter LOS and a lower occurrence of PPCs, providing benefits of postoperative recovery for patients with lung cancer undergoing surgical treatment.

\begin{abstract}
Abbreviations
VATS: Video-assisted thoracoscopic surgery; ERAS: Enhanced recovery after surgery; NSCLC: Non-small-cell lung cancer; VTE: Venous thromboembolism; LMWH: Low-molecular-weight heparin; NRS: Numeric rating scales; PPCs: Postoperative pulmonary complications; SD: Standard deviations; LOS: Length of stay; COPD: Chronic obstructive pulmonary disease; FEV1: Forced expiratory volume in $1 \mathrm{~s}$; FVC: Forced vital capacity.
\end{abstract}

\section{Acknowledgements}

Not applicable.

\section{Authors' contributions}

CW designed the overall study with contributions from YL. YL designed and collected and analyzed data, and cowrote the paper. PL designed and collected and analyzed data with YL and JS designed and carried out the enhanced recovery after surgery. CW, YL, PL and JS discussed and wrote the paper. GC supervised this study, designed and analyzed data and wrote the paper. All authors read and approved the final manuscript.

\section{Funding}

Not applicable.

\section{Availability of data and materials}

The datasets used and/or analysed during the current study are available from the corresponding author on reasonable request.

\section{Ethics approval and consent to participate}

Ethical approval was obtained from the Clinical Trials and Biomedical Ethics Committee of our hospital and Chinese Clinical Trial registry (Registration number: ChiCTR1 900022478). Informed consent were exempted by the Biomedical Ethics Committee of our hospital for the reason listed below: (1) The research data we collected was derived from medical documents. (2) The risk of our research was no greater than minimum risk. (3) We only collected medical data and would not affect patients' right and health. (4) We didn't collect patients' personal information.

\section{Consent for publication}

Not applicable.

\section{Competing interests}

The authors declare that they have no competing interests.

\section{Author details}

${ }^{1}$ Department of Thoracic Surgery, West China Hospital, Sichuan University, Chengdu 610041, People's Republic of China. ${ }^{2}$ Rehabilitation Department, West China Hospital, Sichuan University, Chengdu 610041, People's Republic of China. ${ }^{3}$ Lung Cancer Center, West China Hospital, Sichuan University, Chengdu 610041, People's Republic of China.

Received: 27 June 2020 Accepted: 12 November 2020

Published online: 06 March 2021

\section{References}

1. Ghanem S, El Bitar S, Hossri S, et al. What we know about surgical therapy in early-stage non-small-cell lung cancer: a guide for the medical oncologist. Cancer Manag Res. 2017:9:267-78.

2. Sherwood JT, Brock MV. Lung cancer: new surgical approaches. Respirology. 2007;12:326-32.

3. Boffa DJ, Allen MS, Grab JD, et al. Data from The Society of Thoracic Surgeons General Thoracic Surgery database: the surgical management of primary lung tumors. J Thorac Cardiovasc Surg. 2008;135:247-54.

4. Thomas PA, Berbis J, Falcoz PE, EPITHOR Group, et al. National perioperative outcomes of pulmonary lobectomy for cancer: the influence of nutritional status. Eur J Cardiothorac Surg. 2014;45:652-9.

5. Ha D, Choi H, Zell K, et al. Association of impaired heart rate recovery with cardiopulmonary complications after lung cancer resection surgery. J Thorac Cardiovasc Surg. 2015;149:1168-73.

6. Nicholson A, Lowe MC, Parker J, et al. Systematic review and metaanalysis of enhanced recovery programmes in surgical patients. Br J Surg. 2014;101:172-88

7. Lee L, Mata J, Ghitulescu GA, et al. Cost-effectiveness of enhanced recovery versus conventional perioperative management for colorectal surgery. Ann Surg. 2015;262:1026-33.

8. Joliat GR, Labgaa I, Petermann D, et al. Cost benefit analysis of an enhanced recovery protocol for pancreaticoduodenectomy. Br J Surg. 2015;102:1676-83.

9. Roulin D, Donadini A, Gander S, et al. Cost-effectiveness of the implementation of an enhanced recovery protocol for colorectal surgery. Br J Surg. 2013;100:1108-14.

10. Senturk JC, Kristo G, Gold J, et al. The development of enhanced recovery after surgery across surgical specialties. J Laparoendosc Adv Surg Tech A. 2017;27:863-70.

11. Rogers $L$, Bleetman $D$, Messenger $D E$, et al. The impact of enhanced recovery after surgery (ERAS) protocol compliance on morbidity from resection for primary lung cancer. J Thorac Cardiovasc Surg. 2018;155:1843-52.

12. Das-Neves-Pereira JC, Bagan P, Coimbra-Israel AP, Grimaillof-Junior A, Cesar-Lopez G, Milanez-de-Campos JR, et al. Fast-track rehabilitation for lung cancer lobectomy: a five-year experience. Eur J Cardiothorac Surg. 2009;36:383-91 (discussion 391).

13. Salati M, Brunelli A, Xiumè F, Refai M, Pompili C, Sabbatini A. Does fasttracking increase the readmission rate after pulmonary resection? A case-matched study. Eur J Cardiothorac Surg. 2012;41:1083-7 (discussion 1087).

14. Khandhar SJ, Schatz CL, Collins DT, Graling PR, Rosner CM, Mahajan AK, et al. Thoracic enhanced recovery with ambulation after surgery: a 6-year experience. Eur J Cardiothorac Surg. 2018;53:1192-8.

15. Madani A, Fiore JF, Wang Y, Bejjani J, Sivakumaran L, Mata J, et al. An enhanced recovery pathway reduces duration of stay and complications after open pulmonary lobectomy. Surgery. 2015;158:899-908 (discussion 908).

16. Fiore JF, Bejjani J, Conrad K, Niculiseanu P, Landry T, Lee L, et al. Systematic review of the influence of enhanced recovery pathways in elective lung resection. J Thorac Cardiovasc Surg. 2016;151:708-15.

17. Obi A, Pannucci CJ, Nackashi A, et al. Validation of the caprini venous thromboembolism risk assessment model in critically ill surgical patients. JAMA Surg. 2015;150:941-8. 
18. Fu Y, Liu Y, Chen S, et al. The combination of Caprini risk assessment scale and thrombotic biomarkers to evaluate the risk of venous thromboembolism in critically ill patients. Medicine (Baltimore). 2018;97:e13232.

19. Van Dongen CJ, MacGillavry MR, Prins MH. Once versus twice daily LMWH for the initial treatment of venous thromboembolism. Cochrane Database Syst Rev. 2005;3:CD003074.

20. Seder CW, Salati M, Kozower BD, et al. Variation in pulmonary resection practices between the society of thoracic surgeons and the European society of thoracic surgeons general thoracic surgery databases. Ann Thorac Surg. 2016;101(6):2077-84.

21. Lugg ST, Agostini PJ, Tikka T, et al. Long-term impact of developing a postoperative pulmonary complication after lung surgery. Thorax. 2016;71:171-6.

22. Pearse RM, Moreno RP, Bauer P, et al. Mortality after surgery in Europe: a 7 day cohort study. Lancet. 2012;380:1059-65.

23. Lassen K, Coolsen MM, Slim K, et al. Guidelines for perioperative care for pancreaticoduodenectomy: enhanced recovery after surgery (ERAS) Society recommendations. Clin Nutr. 2012;31:817-30.

24. Melloul E, Hübner M, Scott M, et al. Guidelines for perioperative care for liver surgery: Enhanced Recovery After Surgery (ERAS) Society recommendations. World J Surg. 2016;40:2425-40.

25. Mortensen K, Nilsson M, Slim K, et al. Consensus guidelines for enhanced recovery after gastrectomy: Enhanced Recovery After Surgery (ERASVR) Society recommendations. Br J Surg. 2014;101:1209-29.

26. Batchelor TJP, Rasburn NJ, Abdelnour-Berchtold E, et al. Guidelines for enhanced recovery after lung surgery: recommendations of the Enhanced Recovery After Surgery (ERAS $\left.{ }^{\circledR}\right)$ Society and the European Society of Thoracic Surgeons (ESTS). Eur J Cardiothorac Surg. 2019:55:91-115.
27. Kehlet H, Mogensen T. Hospital stay of 2 days after open sigmoidectomy with a multimodal rehabilitation programme. Br J Surg. 1999;86:227-30.

28. Falcoz PE, Puyraveau M, Thomas PA, et al. Video-assisted thoracoscopic surgery versus open lobectomy for primary non-small-cell lung cancer: a propensity-matched analysis of outcome from the European Society of Thoracic Surgeon database. Eur J Cardiothorac Surg. 2016;49:602-9.

29. Yan TD, Black D, Bannon PG, et al. Systematic review and meta-analysis of randomized and nonrandomized trials on safety and efficacy of videoassisted thoracic surgery lobectomy for early-stage non-small-cell lung cancer. J Clin Oncol. 2009;27:2553-62.

30. Bendixen $M$, Jørgensen OD, Kronborg C, et al. Postoperative pain and quality of life after lobectomy via video-assisted thoracoscopic surgery or anterolateral thoracotomy for early stage lung cancer: a randomised controlled trial. Lancet Oncol. 2016;17:836-44.

31. Li S, Zhou K, Che G, et al. Enhanced recovery programs in lung cancer surgery: systematic review and meta-analysis of randomized controlled trials. Cancer Manag Res. 2017;9:657-70.

32. Brunelli $A$, Thomas $C$, Dinesh $P$, et al. Enhanced recovery pathway versus standard care in patients undergoing video-assisted thoracoscopic lobectomy. J Thorac Cardiovasc Surg. 2017;154:2084-90.

33. Raman JD, Lin YK, Shariat SF, et al. Preoperative nomogram to predict the likelihood of complications after radical nephroureterectomy. BJU Int. 2017;119:268-75.

\section{Publisher's Note}

Springer Nature remains neutral with regard to jurisdictional claims in published maps and institutional affiliations.
Ready to submit your research? Choose BMC and benefit from:

- fast, convenient online submission

- thorough peer review by experienced researchers in your field

- rapid publication on acceptance

- support for research data, including large and complex data types

- gold Open Access which fosters wider collaboration and increased citations

- maximum visibility for your research: over $100 \mathrm{M}$ website views per year

At BMC, research is always in progress.

Learn more biomedcentral.com/submissions 